\title{
Penerapan Model Problem Based Learning Berbantuan Bahan Ajar terhadap Hasil Belajar Kognitif
}

\section{Implementation of The Problem Based Learning Model Assisted Teaching Materials on Cognitive Learning Outcomes}

\author{
Rosalina Sisilia Santriana Son* \\ Sekolah Tinggi Keguruan dan Ilmu Pendidikan (STKIP) SoE \\ *cenari.54@gmail.com \\ diterima : 6 Juni 2021; dipublikasi : 30 Oktober 2021 \\ DOI: $10.32528 /$ bioma.v6i2.5256
}

\begin{abstract}
ABSTRAK
Rendahnya hasil belajar kognitif siswa disebabakan model pembelajaran dan media ajar yang tidak sesuai pada proses pembelajaran. Penelitian ini bertujuan untuk mengetahui peningkatan hasil belajar kognitif siswa. Desain Quasi eksperimen post-test only control group design. Pengambilan sampel purposive sampling. Variabel yang diukur adalah hasil belajar kognitif. Analisis data yang digunakan untuk mengetahui peningkatan hasil belajar kognitif siswa t-test. Hasil penelitian menunjukkan bahwa ada peningkatan hasil belajar kognitif siswa yang dilihat dari perbdaan perbedaan nilai ratarata yang signifikan antara siswa yang belajar menggunakan model PBL dengan bantuan bahan ajar dengan siswa yang menggunakan model konvensional, dimana ratarata hasil belajar kognitif siswa pada kelas ekpserimen 73,5 dan kelas kontrol 60,4, dengan nilai signifikannya adalah 0,340 . Sehingga dapat disimpulkan penerapan model PBL dengan bantuan bahan ajar efektif terhadap hasil belajar kognitif siswa di SMA.
\end{abstract}

Kata Kunci: Bahan Ajar, Hasil Belajar Kognitif, Problem Based Learning,

\begin{abstract}
The low cognitive learning outcomes of students are caused by inappropriate learning models and teaching media in the learning process. This study aims to determine the improvement of students' cognitive learning outcomes. Quasi experimental design post-test only control group design. Sampling purposive sampling. The measured variable is cognitive learning outcomes. Analysis of the data used to determine the improvement of students' cognitive learning outcomes t-test. The results showed that there was an increase in students' cognitive learning outcomes as seen from the significant difference in the average value difference between students who learned to use the PBL model with the help of teaching materials and students who used the conventional model, where the average cognitive learning outcomes of students in the experimental class 73.5 and control class 60.4 , with a significant value of 0.340 . So it can be concluded that the application of the PBL model with the help of teaching materials is effective on the cognitive learning outcomes of students in high school.
\end{abstract}

Keywords: Teaching Materials, Cognitive Learning Outcomes, Problem Based Learning, 


\section{PENDAHULUAN}

Usaha untuk meningkatkan hasil belajar siswa merupakan salah satu tugas dan tanggung jawab seorang guru atau tenaga pendidikan yang profesional. Berbagai upaya pendekatan dalam pembelajaran di kelas telah dilakukan, namun sampai saat ini belum mendapatkan hasil yang memuaskan. Satu dari sekian banyak masalah pendidikan saat ini adalah proses belajar mengajar yang masih berbasis pada guru (teacher center) yang berdampak pada hasil pembelajaran, terutama masalah yang berhubungan dengan kualitas hasil pendidikan. Seorang guru penting untuk menciptakan paradigma baru yang menghasilkan praktik terbaik dalam proses pembelajaran. Pembelajaran bertujuan untuk mengembangkan dimensi sikap, pengetahuan dan ketrampilan melalui perubahan siswa dalam mencari tahu dari aneka sumber belajar yang ada dengan pendekatan ilmiah yang berbasis kompetensi (Kemendikbud, 2013).

Upaya untuk meningkatkan hasil belajar, para ahli menyarankan penggunaan paradigma pembelajaran konstruktif untuk kegiatan belajar mengajar di kelas. Dengan perubahan paradigma belajar konvensional yang berpusat pada guru (teacher center) menjadi belajar yang berpusat pada siswa (student center). Hal ini bisa ditafsirkan bahwa guru di kelas harus berupaya menciptakan kondisi lingkungan belajar yang dapat membelajarkan siswa, mendorong siswa belajar, atau memberi kesempatan kepada siswa untuk aktif dalam proses belajar sehingga siswa lebih mudah memahami konsepkonsep yang dipelajarinya. Pendidikan seharusnya dapat membekali siswa dengan kemampuan- kemampuan yang memungkinkan mereka dapat menghadapi dan menyelesaikan permasalahan dalam kehidupannya nanti. Sementara itu, pembelajaran yang dilakukan di sekolah cenderung hanya sebagai transfer informasi dan pengetahuan yang diberikan oleh guru sebagai faktor dominan.

Keberhasilan pembelajaran dipengaruhi oleh banyak faktor. Salah satu faktor yang berkaitan dengan guru adalah dapat berlangsungnya proses pembelajaran yang efektif, agar pembelajaran menjadi efektif bagi siswa, diperlukan model pembelajaran yang sesuai dengan model belajar siswa (Chatib \& Munif, 2010). Pembelajaran yang melibatkan siswa akan lebih menarik bagi siswa, sehingga dalam pembelajaran siswa benar-benar masuk ke dalam proses belajar.

Bedasarkan hasil observasi yang dilakukan di sekolah tersebut, model pembelajaran yang selama ini dilakukan di SMA Negeri 1 So'E masih menggunakan 
pendekatan lama (teacher center) pembelajaran yang berpusat pada guru. Faktor pendukung lainnya yang mempengaruhi yaitu sebagian besar siswa di SMA Negeri 1 So'E menganggap pelajaran biologi merupakan pelajaran hafalan dengan materi yang banyak, sehingga banyak di antara mereka yang tidak menyukai mata pelajaran biologi, yang mengakibatkan hasil belajar kognitif siswa di bawah KKM yaitu kurang dari 70 .

Rendahnya hasil belajar kognitif siswa dikarenakan proses pembelajaran yang diterapkan selama ini masih menggunakan metode ceramah yang divariasi dengan diskusi informasi, selain itu rendahnya tingkat kemampuan bertanya guru yang mampu membangkitkan motivasi bagi siswa untuk mengikuti proses pembelajaran. Guru cenderung tidak memberikan respon positif terhadap pertanyaan yang telah dirumuskan siswa, sehingga timbul rasa tidak percaya diri dalam diri siswa dan pemahaman siswa terhadap suatu informasi tersebut masih lemah yang mengakibatkan hasil belajar siswa masih rendah. Berdasarkan pernyataan di atas, maka perlu dikembangkan sebuah model pembelajaran untuk membangkitkan semangat peserta didik agar aktif dalam proses pembelajaran.

Salah satu model pembelajaran yang relevan dalam pembelajaran biologi adalah model pembelajaran berbasis masalah (problem based learning ). Pada prinsipnya dalam model pembelajaran PBL siswa dituntut untuk secara aktif mencari jawaban atas masalah-masalah yang diberikan guru. Dalam hal ini guru lebih banyak sebagai mediator dan fasilitator untuk membantu siswa dalam mengkonstruksi pengetahuan mereka secara efektif. Pembelajaran berbasis masalah merupakan pembelajaran yang menyajikan kepada siswa situasi masalah yang nyata, yang bersifat terbuka (ill-structured). Pandangan konstruktivisme tentang model PBL menempatkan siswa sebagai konstruktor aktif dari pengetahuan secara fleksibel. Pengetahuan dipelajari dalam konteks bermakna yang serupa dengan di mana pelajar mengaplikasikan pengetahuan selanjutnya. PBL juga memfasilitasi pengembangan keterampilan belajar kognitif dan memberikan motivasi belajar intrinsik. Posisi guru sebagai fasilitator dalam PBL, bertugas untuk membantu memberikan pengalaman pada siswa dalam mendesain memecahkan masalah yang terkait dengan materi pelajaran. Siswa diharapkan mampu berinteraksi untuk menghasilkan solusi dari permasalahan. Dalam kelas PBL juga terjadinya komunikasi secara efektif dan siswa mampu berkolaborasi dengan siswa lain dalam melakukan percobaan (Cennamo et all, 2011). 
Beberapa hasil penelitian tentang model PBL menemukan bahwa model PBL lebih baik daripada model pembelajaran konvensional yang biasa dilaksanakan di sekolah. Prestasi belajar siswa pada mata pelajaran biologi dengan menggunakan model PBL mengalami peningkatan. Sehingga model ini perlu untuk diimplementasikan, serta dikembangkan bukan hanya pada mata pelajaran biologi, akan tetapi juga pada mata pelajaran lain yang sesuai. Karena strategi ini selain meningkatkan prestasi belajar siswa, strategi ini juga sangat berguna dalam melatih siswa untuk memecahkan masalah.

Selain model pembelajaran yang berpengaruh terhadap hasil belajar kognitif siswa, hasil belajar siswa juga dipengaruhi oleh sumber dan media belajar yang di sediakan dalam proses pembelajaran. Salah satu kondisi eksternal yang berpengaruh pada belajar adalah bahan ajar. Bahan ajar dalam pembelajaran dapat berwujud benda dan isi pendidikan. Isi pendidikan tersebut dapat berupa pengetahuan.

Berdasarkan permasalahan telah dilakukan penelitian ekperimen mengenai “ Pengauh Bahan Ajar dan Model PBL terhadap Hasil belajar Siswa SMA”. Tujuan penelitian ini adalah untuk mengetahui peningkatan hasil belajar kognitif siswa dengan penerapan model Problem Based Learning berbantuan bahan ajar.

\section{METODE}

Jenis penelitian yang digunakan adalah Quasi Experimental untuk membandingkan perlakuan belajar mengajar pada kelas eksperimen dan kelas kontrol. Desain penelitian yang digunakan adalah post-test only control group design (Millan \& Schumacher, 2001). Desain eksperimen penelitian disajikan pada tabel 1.

Tabel 1. Desain penelitian

\begin{tabular}{ccc}
\hline Group & Treatment & Postest \\
\hline $\mathrm{A}$ & $\mathrm{X}_{1}$ & $\mathrm{O}$ \\
$\mathrm{B}$ & $\mathrm{X}_{2}$ & $\mathrm{O}$ \\
\hline
\end{tabular}

Keterangan:
A : Kelas eksperimen
B : Kelas kontrol
X1 : Perlakuan dengan bahan ajar dengan model PBL
$X_{2}$ : Perlakuan dengan pembelajaran konvensional
O : Post-test 
Tabel 1 menunjukkan pada kelas eksperimen dilaksanakan pembelajaran dengan model pembelajaran PBL berbantuan bahan ajar $\left(\mathrm{X}_{1}\right)$ dan pada kelas kontrol meggunakan pembelajaran konvensional $\left(\mathrm{X}_{2}\right)$. Pada akhir pembelajaran, siswa di kedua kelas mendapat tes akhir $(\mathrm{O})$.

Instrumen yang digunakan dalam penelitian ini meliputi perangkat pembelajaran. Perangkat pembelajaran terdiri dari silabus, rencana pelaksanaan pembelajaran (RPP) dan lembar kerja siswa (LKS) untuk kelas eksperimen. Instrument pengukuran berupa tes. Sebelum menggunakan intrumen tes, dilakukan uji validasi, reliabel, tingkat kesukaran dan daya pembeda soal.

Tes dilakukan untuk mengukur kemampuan kognitif siswa pada konsep tentang materi yang telah disampaikan. Bentuk soal tes yang digunakan adalah soal pilihan ganda yang berjumlah 30 soal. Tes yang digunakan dalam penelitian ini post test.

Teknik analisis data yang digunakan peneliti pada penelitian ini adalah analisis statistik menggunakan analisis t-test dengan bantuan program SPSS versi 17.0 for windows yang sebelumnya dilakukan uji prasyarat yakni uji normalitas dan uji homogenitas.

\section{HASIL PENELITIAN DAN PEMBAHASAN}

Sebelum menggunakan uji t-test, terlebih dahulu dilakukan pengujian normalitas dan homogenitas variansi kedua kelompok. Berdasarkan uji Shapiro-Wilk tentang Test of Normality dengan taraf signifikansi $\alpha=0,05$, maka diperoleh nilai Sig. $=$ 0,079. Nilai signifikansi > 0,05 sehingga dapat disimpulkan bahwa data nilai postetst pada kedua kelas berdistribusi normal. Selanjutnya, dilakukan uji homogenitas pada kedua sampel penelitian. Uji homogenitas varians menggunakan uji Levene dengan taraf signifikansi $\alpha=0,05$. Berdasarkan uji Levene untuk uji homogenitas variansi kedua sampel penelitian diperoleh nilai Sig. $=0,340$. Karena nilai Sig. $=0,340>0,05$ maka dapat disimpulkan bahwa nilai Postets pada kedua kelas penelitian mempunyai variansi yang homogen.

Analisis data komparatif hasil belajar kognitif siswa pada kelas ekpserimen dan kelas kontrol dilakukan uji $t$ dengan taraf signifikansi $\alpha=0,05$ menggunakan software SPSS 17 ditunjukkan pada Gambar 1. 


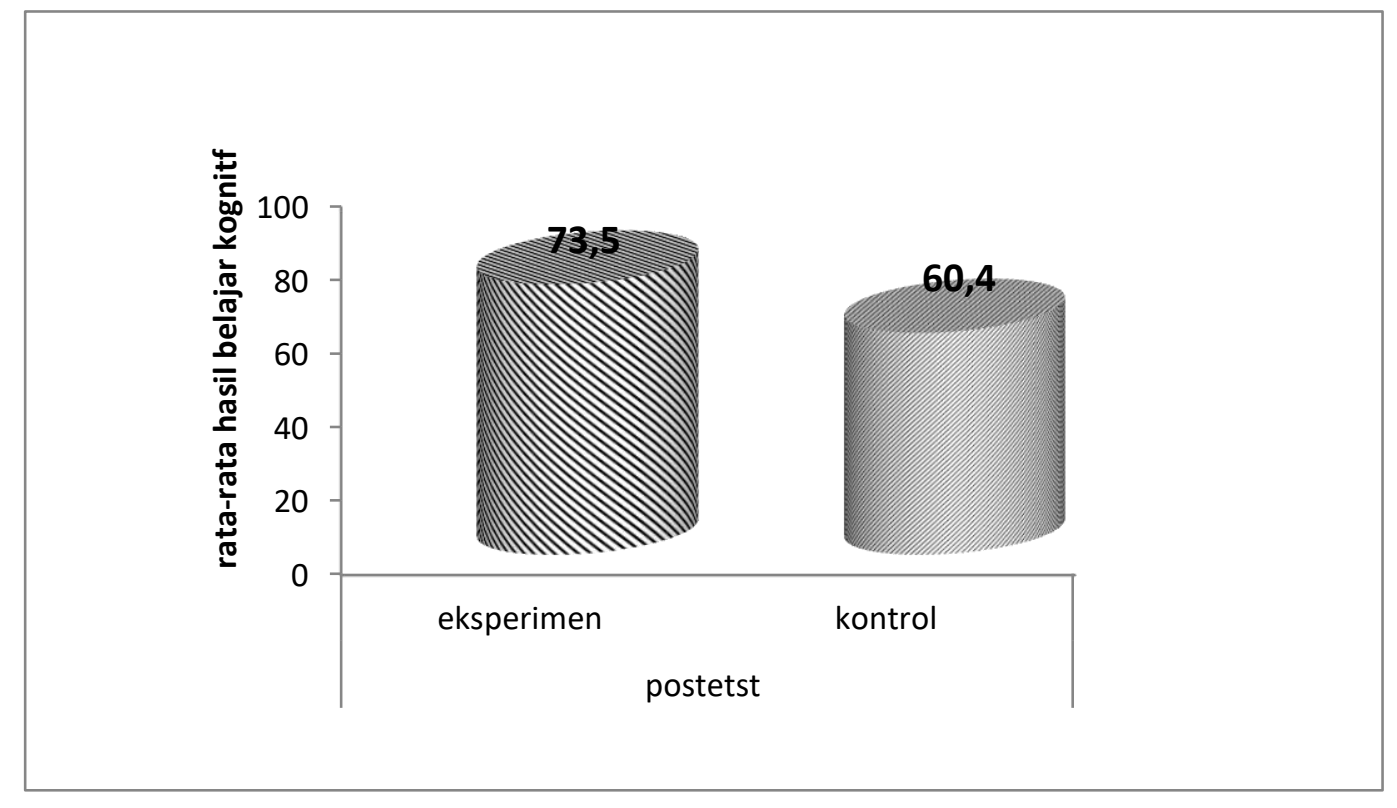

Gambar 1. Rata-rata Hasil Belajar Kognitif Siswa Post-test

Rata-rata hasil belajar kognitif antara kelas eksperimen $(73,5)$ dengan kelas kontrol $(60,4)$ menunjukkan adanya perbedaan yang signifikan. Hal ini menunjukkan bahwa pembelajarn yang dilakukan dengan penerapan bahan ajar dengan model PBL efektif terhadap hasil belajar kognitif siswa.

Hasil analisis independent sample test menunjukkan bahwa $t_{\text {hitung }}(7,359)>$ $\mathrm{t}_{\text {tabel }} 5 \%(2,042)$ sehingga Ha yang menyatakan adanya perbedaan rata-rata skor hasil belajar kognitif antara kelas eksperimen dan kelas kontrol diterima, dengan nilai signifikansinya dapat di lihat pada tabel 1 . 
Tabel 1. Independent Samples Test

\begin{tabular}{|c|c|c|c|c|c|c|c|c|c|c|}
\hline & & \multicolumn{4}{|c|}{$\begin{array}{l}\text { Levene's Test } \\
\text { for Equality of } \\
\text { Variances }\end{array}$} & \multicolumn{3}{|c|}{ t-test for Equality of Means } & \multirow{2}{*}{\multicolumn{2}{|c|}{$\begin{array}{l}95 \% \text { Confidence } \\
\text { Interval of the } \\
\text { Difference }\end{array}$}} \\
\hline & & \multirow[b]{2}{*}{$\mathrm{F}$} & \multirow[b]{2}{*}{ Sig. } & \multirow[b]{2}{*}{$\mathrm{t}$} & \multirow[b]{2}{*}{ df } & \multirow{2}{*}{$\begin{array}{l}\text { Sig. (2- } \\
\text { tailed) }\end{array}$} & \multirow{2}{*}{$\begin{array}{c}\text { Mean } \\
\text { Difference }\end{array}$} & \multirow{2}{*}{$\begin{array}{l}\text { Std. Error } \\
\text { Difference }\end{array}$} & & \\
\hline & & & & & & & & & Lower & Upper \\
\hline \multirow[t]{2}{*}{ hasil belajar } & $\begin{array}{l}\text { Equal } \\
\text { variances } \\
\text { assumed }\end{array}$ & .926 & .340 & 7.359 & 58 & .000 & 13.100 & 1.780 & 9.537 & 16.663 \\
\hline & $\begin{array}{l}\text { Equal } \\
\text { variances } \\
\text { not } \\
\text { assumed }\end{array}$ & & & 7.359 & 57.295 & .000 & 13.100 & 1.780 & 9.536 & 16.664 \\
\hline
\end{tabular}

Hasil penelitian pada Gambar 1 menunjukkan bahwa rata-rata nilai hasil belajar siswa di kelas eksperimen lebih tinggi dibandingkan siswa di kelas kontrol. Berdasarkan uji statistik nilai hasil postest pada kelas ekperimen dan kontrol terbukti berbeda secara signifikan. Berdasarkan deskripsi data hasil penelitian, kelompok siswa yang mengikuti pembelajaran dengan model PBL memiliki hasil belajar yang lebih tinggi dibandingkan dengan kelompok siswa yang mengikuti pembelajaran dengan model konvensional. Tinjauan ini didasarkan pada rata-rata skor hasil belajar siswa. Hasil ini menunjukkan bahwa penerapan bahan ajar dengan model PBL efektif terhadap hasil belajar siswa. Peningkatan hasil belajar kognitif siswa juga dibuktikan dengan melakukan uji $t$, dimana nilai signya adalah 0,340 , menyatakan bahwa penerapan model PBL berbantuan bahan ajar dapat meningkatkan hasil belajar kognitif siswa.

Penelitian tersebut didukung oleh penelitian (Prandyana et al, 2013) dengan judul "pengaruh Pembelajaran Berbasis Masalah terhadap Motivasi Belajar dan Prestasi Belajar Matematika Siswa Kelas VI SD" Prandyana mengemukan bahwa terdapat perbedaan motivasi dan hasil belajar yang signifikan antara siswa yang mengikuti pembelajaran dengan penerapan bahan ajar model PBL dengan siswa yang mengikuti pembelajaran secara konvensional, dimana hasil belajar siswa yang mengikuti pembelajaran dengan model PBL lebih tinggi dibandingkan dengan siswa yang mengikuti pembelajaran secara konvensional. Hal ini sejalan dengan penelitian (Mahendra et al, 2014), dimana terdapat perbedaan hasil belajar IPA yang signifikan antara siswa yang mengikuti model pembelajaran berbasis masalah dengan siswa yang 
mengikuti model pembelajaran Konvensional pada siswa kelas V SD di gugus XV Kecamatan Buleleng Tahun Ajaran 2013/2014.

Hasil penelitian menunjukkan meningkatkan keterampilan proses Presentase kenaikan keterampilan pemecahan masalah sebesar 9,09\% untuk siklus 1, 11,36\% untuk siklus 2, 13,63\% untuk siklus 3. b) meningkatkan presentase jumlah siswa yang mencapai ketuntasan belajar minimal (KKM) pada Bahasa Indonesia sebagai berikut : pada kondisi awal presentase pencapaian KKM sebesar 22,7\% (5 siswa), pada siklus 1 presentase meningkat menjadi 40,9\% (9 siswa), pada siklus 2 presentase meningkat menjadi 59,09\% (13 siswa), pada siklus 3 presentase meningkat menjadi 72,72\% (16 siswa). Sedangkan untuk Matematika pada kondisi awal presentase pencapaian KKM sebesar 36,36\% (8 siswa), pada siklus 1 presentase meningkat menjadi 36,36\% (8 siswa), pada siklus 2 presentase meningkat menjadi 63,63\% (14 siswa), pada siklus 3 presentase meningkat menjadi 77,27\% (17 siswa).

Perbedaan yang signifikan antara kelompok siswa yang mengikuti pembelajaran dengan model PBL dengan kelompok siswa yang mengikuti pembelajaran menggunakan model konvensional disebabkan karena pembelajaran dengan model PBL menekankan aktivitas siswa lebih banyak dibandingkan guru melalui pembelajaran antar kelompok dengan pemberian masalah, dengan demikian, keaktifan siswa dalam belajar membuat mereka mendapatkan pengetahuan secara bermakna dan tidak membosankan dan penggunaan bahan ajar, lembar kerja siswa, dan lingkungan sebagai sumber belajar yang dilakukan dalam proses pembelajaran, sehingga meningkatkan pemahaman dan pengetahuan siswa akan materi yang sedang dipelajari dan berdampak pada hasil belajar kognitif siswa menjadi lebih baik.

\section{KESIMPULAN DAN SARAN}

Berdasarkan hasil penelitian dan pembahasan di atas, maka dapat disimpulkan sebagai berikut. Terdapat perbedaan hasil belajar kognitif pembelajaran yang signifikan antara siswa yang mengikuti proses pembelajaran menggunakan model PBL dengan siswa yang mengikuti model pembelajaran Konvensional pada siswa kelas X SMA Negeri 1 So'E. Rata-rata model pembelajaran berbasis masalah $=73,5>$ rata-rata konvensional $=60,4$ Adanya perbedaan, dengan hasil analisis uji $t$ nilai $\alpha=0,340$, yang menunjukkan bahwa model PBL dengan bahan ajar berpengaruh positif terhadap 
hasil belajar kognitif siswa dibandingkan dengan model konvensional, yang dilihat dari peningkatan hasil belajar kognitif siswa.

Berdasarkan hasil penelitian ini, maka dapat diajukan beberapa saran sebagai berikut. (1) Bahan ajar dengan model PBL hendaknya dapat diimplementasikan dan dikembangkan dilapangan sebagai alternatif pembelajaran khususnya dalam upaya meningkatkan hasil belajar kognitif siswa. (2) Kemudian bagi peneliti lain hasil penelitian ini diharapkan menjadi salah satu sumber informasi untuk mengadakan penelitian lebih lanjut tentang model PBL dengan bahan ajar dalam bidang ilmu biologi maupun bidang ilmu lainnya, agar memperhatikan kendala- kendala yang dialami dalam penelitian ini sebagai bahan pertimbangan untuk perbaikan dan penyempurnaan penelitian yang akan dilaksanakan.

\section{DAFTAR RUJUKAN}

Achyani., Rustaman, N., Redjeki, S., \& Choesin, D. (2010) "Model Penulisan Buku Ajar Biologi SMA Berwawasan Ekologi dan Lokal untuk Meningkatkan Kepedulian Siswa terhadap Lingkungan". Jurnal Penelitian Pendidikan UMM. 1 (1): 6-10

Arends, R. (2008). Learning To Teach. Yogyakarta: Pustaka Belajar

Barrow., C.J. (2005). Environmental Management and Development. Routledge, London

Binadja., A. (2015). Pedoman Praktis Pengembangan Bahan Pembelajaran Berdasar Kurikulum 2004 Bervisi dan Berpendekatan SETS. Semarang: Laboratorium SETS Unnes.

Binadja, A., Wardani \& Nugroho, S. (2008). "Keberkesanan Pembelajaran Kimia Materi Ikatan Kimia Bervisi SETS pada Hasil Belajar Siswa". Jurnal Inovasi Pendidikan Kimia. 2 (2): 256-262

Cennamo. K., Brandt. C., Scott. B., Douglas. S., McGrath. M., Reimer. Y \& Vernon. M. (2011). Managing the Complexity of Design Problems through Studiobased Learning.The Interdisciplinary Journal of Problem-Based Learning. 5 (2).

Chatib., \& Munif. (2010). Sekolahnya Manusia (Sekolah Berbasis Multple Itelligences di Indonesia. Bandung : Kaifa

Dimyati., \& Mudjiono. (2012). Belajar dan Pembelajaran. Jakarta: PT Rajagrafindo Persada

Daryanto. (2014). Pembelajaran Tematik, Terpadu, Terintegrasi (Kurikulum 2013). Yogyakarta: Gava Media.

Husna., A., Fianti., \& Cahyono., E. (2019). The Effect of Project Based Learning Model Aided Scratch Media Toward Learning Outcome and Creativity. Journal of Innovative Science Education, 8 (1), 1-7. 
Kemendikbud. (2013). Permendikbud RI No 65 Tahun 2013 tentang Standar Proses Pendidikan Dasar dan Menengah. Jakarta: Kemendikbud.

Mahendra., K. Sumantri., M. \& Margunayasa., I. G. (2014). Pengaruh Model Pembelajaran Berbasis Masalah Terhadap Hasil Belajar IPA Siswa Kelas V. eJournal Mimbar PGSD Universitas Pendidikan Ganesha Jurusan PGSD, 2(1), 189-198.

Majid, A. (2011). Perencanaaan Pembelajaran. Bandung: PT Remaja Rosdakarya.

Millan., J. H., \& Schumarcher,S. (2011). Research in Education, Fifth Edition. New York: Longman.

Normala.,R.N., \& Indri., A. (2017). Peningkatan Aktivitas Belajar Matematika Melalui Pendekatan Problem Based Learning bagi Siswa Kelas IV SD. Scholaria. Jurnal Pendidikan dan Kebudayaan, 7 (3), 241-250.

Pradnyana.,P.B. Marhaeni., A.A.I.N. Candiasa., \& I Made. (2013). Pengaruh pembelajaran Berbasis Masalah Terhadap Motivasi Belajar dan Prestasi Belajar Matematika Siswa Kelas VI SD. Jurnal Program Pasca Sarjana Universitas Pendidikan Ganesha Jurusan, 3(3), 207-2017.

Prastowo., A. (2012). Pengembangan Sumber Belajar. Yogyakarta: Pedagogia.

Rachmawati., L. (2011). Penerapan Model Problem Based Learning (PBL) untuk Meningkatkan Pembelajaran IPA Siswa Kelas V SD Negeri Pringapus 2 Kecamatan Dongko Kabupaten Trenggalek. Skripsi Universitas Negeri Malang.Rifa'i, Achmad dan Catharina Tri Anni. 2009. Psikologi Pendidikan. Semarang:Universitas Negeri Semarang Press.

Rusman. (2012). Model-model Pembelajaran Mengembangkan Profesionalisme Guru. Jakarta: Raja Grafindo Persada.

Slamento. (2010). Belajar dan Faktor-Faktor yang Mempengaruhinya. PT Rineka Cipta.

Sudjana, Nana. (2010). Penilaian Hasil Proses Belajar Mengajar. Bandung: PT. Remaja Rosdakarya.

Suprijono, Agus. (2010). Cooperative Learning Teori dan Apikasi PAIKEM. Yogyakarta: Pustaka Pelajar.

Warsono., \& Hariyanto. (2013). Pembelajaran Aktif. Bandung: PT. Remaja Rosdaskarya. 